\title{
Faculty prepares for independence with new Board
}

The Faculty of General Dental Practice (UK) (FGDP[UK]) has announced new Board members following elections earlier this year, and an inaugural meeting on 30 June 2017.

Consisting of representatives of one or more of the local divisions, the Faculty Board decides the strategic direction of the FGDP(UK) and oversees its implementation. The new Board will now focus its attention on preparing the Faculty for independence from the Royal College of Surgeons, as announced on 30 January 2017.

New Board members include Susan Nelson, a principal dentist specialising in restorative dentistry and orthodontics, elected to represent Northern Ireland. Roshni Karia has been elected to represent SE/SW Thames having previously played a role as Early Career Representative as an Observer to the Board.

Each elected Board member serves a three-year term.

Mick Horton, Dean of FGDP(UK) said: 'This year we are celebrating a quarter century, in which we have built a secure home for general practice dentistry, with a bold move towards independence. We welcome all of our new and re-elected Board members who support our work in 2017 as we strengthen our membership to build a rich community of shared expertise and experience, work to foster career pathways for all those working in general practice and establish standards in dentistry that are led by the profession.'

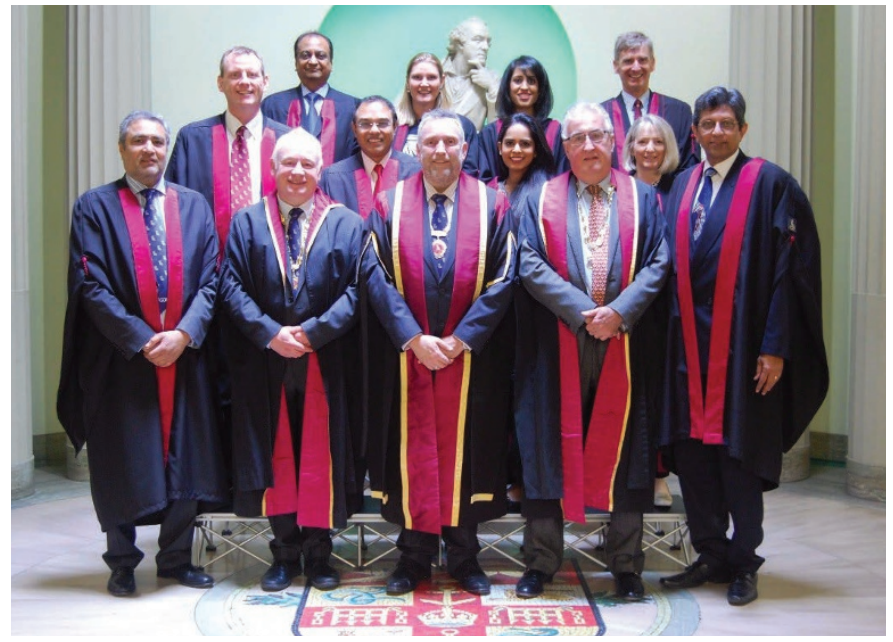

Front Row (L-R): Onkar Dhanoya, Ian Mills (Senior Vice Dean), Michael Horton (Dean), Paul Batchelor (Junior Vice Dean), Nik Pandya

Middle Row (L-R): Jonathan Farmer, Abhi Pal, Reena Wadia, Patricia Thomson Back Row (L-R): Pankaj Patel, Susan Nelson, Roshni Karia, Mark Richardson

To read the full story, visit http://www.fgdp.org.uk/content/news/ new-look-board-announced-as-fgdpuk-prepares-for-in.ashx.

\section{Children's oral health improving in Wales}

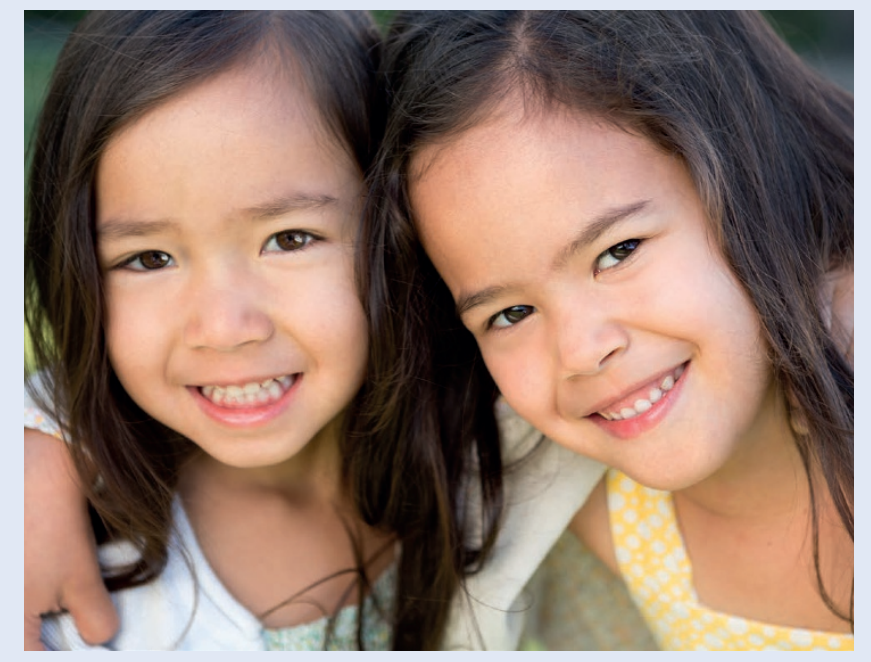

The proportion of five-year-old children with poor dental health in Wales is continuing to fall, with children from the most deprived backgrounds seeing the biggest reduction in tooth decay over the last decade, a new report published in July shows.

The report by Public Health Wales is the latest dental survey of five-year-old children in Wales, undertaken by the Welsh Oral Health Information Unit, as part of the NHS dental survey programme.

The report shows:

- A reduction in the proportion of children with decay between 2007-08 (47.6\%) and 2015-16 (34.2\%). This represents continuing improvement of the proportion of children who have no obvious decay experience by age five. In 2015-16 in a class of 30 children 20 will have no decay experience. This compares with 16 decay free in a class of 30 children in 2007-08

- The all-Wales mean decay experience ( $\mathrm{dmft}$ ) has also continued to reduce from 1.98 in 2007-08 to 1.22 in 2015-16. This represents a $38 \%$ reduction in mean $\mathrm{dmft}$ scores in nine years

- In 2007-08, 14 children out of a class size of 30 would have decay experience, with an average of 4.2 teeth affected. By 2015-16 this had fallen to ten children out of a class of 30 , with an average of 3.6 decayed teeth

- Dental disease levels in children in Wales continue to improve across all social groups. In absolute terms, the most deprived quintile have seen the largest reduction in decay prevalence (by $15 \%$ ) and mean $\mathrm{dmft}$ score (by 0.6 ). There is no evidence of widening inequalities.

Chief Dental Officer for Wales, Dr Colette Bridgman, said: 'Although we've seen great improvements in tooth decay in school year 1 children over the last decade or so, there is scope for further improvement for the third of children still experiencing tooth decay.

'We know that dental decay starts early. Typically, half of the decay experienced at five years of age will be evident by age three. Therefore, primary intervention will have most impact before the age of three, so we are re-focussing Designed to Smile on the 0-5 age group, restating the overarching aim of the programme, to keep children decay free by the age of five.' 